\title{
Managing uncertainty: Forest professionals' claim and epistemic authority in the face of societal and climate change
}

\author{
Rolf Lidskog* and Erik Löfmarck \\ Environmental Sociology Section, HumUS, Örebro University, Örebro SE-701 \\ 82 Sweden. \\ E-mails: Rolf.lidskog@oru.se; erik.lofmarck@oru.se \\ ${ }^{*}$ Corresponding author.
}

\begin{abstract}
How do professional experts develop advice in the face of uncertainty? The background for this question is that uncertainties threaten all forms of expertise because they risk calling the professional claim into question and undermine the professional's epistemic authority. Adopting a multidimensional concept of uncertainty as its point of departure, this article focuses on how a specific category of experts - forest professionals - encounter and cope with uncertainty in their counselling activities, particularly uncertainty related to climate change. The empirical material consists of an interview study of publicly employed forest consultants in Sweden. The analysis identifies seven strategies that are applied to cope with uncertainties. The findings indicate that a multidimensional concept of uncertainty can explain why cognitive uncertainty is more easily managed than other types of uncertainty. Moreover, uncertainty may not be a central obstacle to offering advice; rather it can be actively used to gain authority and influence action.
\end{abstract}

Risk Management (2015) 17, 145-164. doi:10.1057/rm.2015.10

Keywords: expertise; epistemic authority; professional claim; uncertainty; climate change; forestry

The online version of this article is available Open Access

\section{Introduction}

$\mathrm{P}$ rofessional expertise is pivotal in our society. Through their competence, authority and mandate, experts offer guidance to organizations and individuals concerning how to address and decide issues 
that are remote from their everyday knowledge. Among other factors, the changing nature of risk (Smith and Fischbacher, 2009) has been an important source of the increased dependency on experts. A number of sociologists, including Beck and Giddens, have discussed this situation, highlighting expert-dependency and its implications in late modern societies. Because of the increased role of technology and science, citizens and organizations seem to have no choice but to trust experts. Organizations and governments increasingly make use of expert knowledge as a means of steering society, and knowledge making and policymaking have become increasingly related and intertwined (Miller, 2001; Lidskog and Sundqvist, 2013). In a complex and diffuse political landscape, science is an emerging measure of social power, and policy analysts have contended that the cognitive stabilization provided by expertise can be used to counterbalance the political destabilization of the nation-state (Barry et al, 1996; Haas and Stevens, 2011). Thus, we live in a society in which many risks are fundamentally research-dependent and experts have a central role in guiding policymaking in addition to their professional work.

However, other sociologists stress that expertise is in turmoil and science's capacity to deliver trustworthy and relevant knowledge is contested (Irwin and Michael, 2003). Moreover, science is de-stabilized in the sense that it is no longer necessarily presumed to offer true and un-contested knowledge. One reason for this is the increasing stress placed on the uncertainty of all knowledge claims, a position that is frequently articulated by scientists, stakeholders and the general public (Lidskog, 2008). Another reason is that expert knowledge flourishes in many institutional settings, resulting in a multitude of partly contradictory expert messages concerning how to decide and act (Pfadenhauer, 2006; Navin, 2013). A third reason is that citizens have - not least through mass education - developed a competence to critically evaluate knowledge claims, meaning that expert knowledge is not taken for granted but has to be negotiated to be considered legitimate, valid and trustworthy (Nowotny et al, 2001). Opportunities arise for contesting and negotiating specific risks when organizations and individuals regard expertise as having no privileged access to truth and risk assessments as resting on numerous questionable assumptions. This situation - which is extensively discussed elsewhere (cf. Nowotny et al, 2001; Collins and Evans, 2007; Callon et al, 2009; Lidskog and Sundqvist, 2013) - results in new conditions for expertise and how to develop guidance in a context of contestation and uncertainty. Thus, we observe the cognitive destabilization of expert claims, which has left political bodies and expert communities pondering how to develop a more robust - socially accepted and publicly trusted - expertise (Lofstedt, 2005; van Asselt and Renn, 2011). In addition, there are arguments for the importance of developing a new type of expertise, in which epistemic authority (that is, a social position for authoritatively delivering recommendations within a specific domain) is negotiated and developed in 
interaction with the organizations it aims to influence (Raviv et al, 1993; Pfadenhauer, 2006). Expertise is still considered pivotal in transforming uncertainties into governable risks (Lidskog and Sjödin, 2015). However, the conditions that expertise must satisfy to fulfil this function have changed; experts must now address both their own internal uncertainty (what advice to give) and their authority (how to make the advice trustworthy). Thus, it is more the rule than the exception that organizations make decisions based on insufficient or uncertain knowledge, and professional expertise is central for guiding decisions and actions.

These circumstances represent the point of departure for this article, which focuses on strategies for providing professional expertise in the context of uncertainty. The empirical aim of this contribution is to study a specific group of professional experts: forest consultants in Sweden. There are at least three reasons for investigating them: (i) Sweden's de-regulated forest management system heavily relies on social norms and knowledge distribution to shape forest owners' actions. Forest counselling is thus a central instrument for steering Swedish forestry; (ii) uncertainties caused by the long-term perspective that must be considered in forestry (the rotation period for Swedish forestry is 60-80 years, which means that the future consequences of climate change and a number of other environmental and non-environmental issues must be considered); and (iii) the increasing complexity of the target audience of forest counselling. This complexity arises because on-going changes in ownership structures (not least due to urbanization processes) mean that an increasing number of forest owners live remote from their forest properties and possess limited knowledge of forest practices. Thus, forest consultants serve as an illustrative case of a growing professional challenge: providing advice in the presence of uncertainty. In addition to these reasons, there is a fourth: the growing need to study risk governance in practice, not least the practical and contextual reasoning of 'street-level' managers (Corvellec, 2009; Boholm, 2010), which is the focal point of this study.

Using an interview study, this article investigates how forestry consultants provide guidance on issues affected by uncertainty. A particular focus is on climate change, an issue that is simultaneously a high political priority and affected by considerable uncertainty. How do forest consultants cope with a situation in which there is a strong demand for action to create forests that are less sensitive to climate change in an area that is also affected by numerous uncertainties? The research questions are as follows: What are the main challenges facing forest consultants when striving to maintain epistemic authority? How do they approach uncertainties in their counselling work? The article is organized into five parts, this introduction included. The second part develops the theoretical approach applied in the study, describes the relationship between expertise and professions and addresses different aspects of uncertainty. The third part outlines the design of the study, including empirical 
area studies and the methods and data used. The fourth part presents the results of the interview study, beginning with the challenges faced by the forest consultants in their counselling activities, followed by the strategies they have developed to cope with these challenges. The fifth and concluding part discusses the implications of having no option but to acknowledge uncertainties when providing counselling services.

\section{Professions and Negotiated Expertise}

Research has shown that it is often difficult to find solutions when knowledge is scattered and uncertain, when there are different conceptualizations of the problem, and when the actors involved prioritize the issue at stake differently. If no general definition is agreed upon, there is rarely any opportunity to formulate a joint plan for concerted action (Schön and Rein, 1994; Palmer, 2012). Even in cases involving a hierarchical model of regulation, making and implementing decisions may be difficult if there are too many voices against a proposal. In cases where regulation is primarily based on norms and knowledge, discursive closure is essential because in this case there is a need for the actors involved to share a common definition of the problem that can guide their actions. Professional expertise - the task of which is to conduct or suggest relevant interventions (Brante, 2011) - is needed to know not only what the problem is but also how to address it. Through their epistemic authority, experts define, describe and explain bounded domains of reality, which facilitates for clients to make decisions and develop actions.

The definition of the concept of 'professional expertise' stresses organizational positions and specialist knowledge. Traditionally, professions are defined as being based on licence (the exclusive permission to perform and implementspecific tasks) and mandate (to prescribe how others must act) (Hughes, 1981). Jurisdiction - who has monopoly and control over a set of tasks - serves as the link between professionals and their work (Abbott, 1988). Jurisdiction establishes the limits of the professional's authority, mandate and legitimate scope of action. In addition, professions are attached to a body of knowledge; to become part of a profession, a candidate must prove that he or she has acquired certain knowledge relevant for the profession (in most cases through an educational programme at the university level) (Pfadenhauer, 2006). This focus implies that organizational dimensions are made central, how educational programs are developed, associations formed, professional jurisdictions and legal mandates negotiated, and organizational boundaries drawn (Eyal, 2013). The content what professionals actually do, how they make use of knowledge and how they address competing knowledge claims - is much less researched. However, this is the focus of the sociology of expertise. 
An expert is commonly defined as 'someone who masters skills with recognized (indeed certified) competence which is called upon in decisionmaking processes' (Callon et al, 2009, p. 228). In modern society, experts are pivotal due to their provision of the cognitive, technical and/or organizational knowledge necessary for monitoring and control systems (Giddens, 1990; Reed, 1996). Expertise is always based in a claim of possessing specialized knowledge, competence and skill. In that sense, expertise is also characterized by having a jurisdiction: expertise constructs experts' epistemic authority and credibility by drawing sharp boundaries between scientific facts (which scientists should determine) and publicly debatable and value-laden judgements (which citizen, political representatives and others should determine), implying that all knowledge claims outside the expert domain are de-legitimated as not being scientific (Gieryn, 1999). Expert status is achieved by carving out and controlling a particular knowledge area and then asserting one's authority as the provider of relevant knowledge for problem-solving within this area. Through this boundary work, a certain type of knowledge - expert knowledge - is accorded the legitimacy to define, describe and explain bounded domains of reality. An important difference, however, is that the jurisdiction of expertise is rarely of a juridical or quasi-juridical character, in contrast to a profession, which has a formally regulated mandate. It is, for example, possible to assert that one is a lay-expert on certain issues but not a lay-professional. This means that most professionals are also experts (due to their base in scientific knowledge), whereas not all experts are professionals (due to the possibility of gaining specialist knowledge in an 'uncertified' way, that is, without formal training, but also because their expertise may not necessarily be connected to their occupation). This makes the 'problem of extension' (Collins and Evans, 2007) more present and pressing for experts than professions; many claim to possess expert knowledge, and hence it is difficult for clients to know who to trust. In addition to this difference, there are a number of similarities between experts and professions, not least that they both strive for epistemic authority, a position from which they can influence their clients' thoughts and actions through cognitive means. Experts and professionals consistently make claims that they possess better knowledge of a certain matter than do others, and if this claim is trusted, they are positioned to influence others (Hughes, 1963; Abbott, 1988; Collins and Evans, 2007; Callon et al, 2009). The professional claim is dynamically and dually related to professional expertise and its clients; claims are trusted because they are considered relevant and arrive from trusted sources (professional expertise), and the professional experts maintain their authority and position by delivering relevant guidance for their clients.

Forest consultants are a type of professional expert; they are accorded a special mandate (through existing regulation) that other experts do not possess, while their knowledge base is not exclusive but open to and challenged by other specialists. A particular problem for professional experts is to gain authority. 
In contemporary society, authority is to a large extent contested and negotiated (Beck and Beck-Gernsheim, 2004). Authority is not given but has to be earned, and therefore, professional experts must take the client's understanding of a problem more seriously, both to be able to provide relevant guidance and to be trusted by those whose action it seeks to influence (cf. Raviv et al, 1993; Pfadenhauer, 2006). This is clearly the case for forest consultants. Both the character of the forest and the interest and competence of forest owners must be considered to offer advice that is both deemed relevant and likely to be heeded. A particular problem in this regard is that the knowledge of professional experts may be questioned by their clients, or at least relativized. As Giddens (1991, p. 137) has shown, while expert systems have intruded all aspects of society and, thereby, deskilled citizens to a large extent, other (partly compensatory) skills have developed. Not least of which is the dramatic growth in the accessibility of knowledge through information technology, which has made information-seeking capacity central. This means that nearly everyone can not only form an opinion on a knowledge-dependent issue but also provide with facts that support this opinion (and/or question those of others) (Webster, 2002). Forest owners may, through their own work with forestry and/or knowledge acquisitions, similarly obtain knowledge and form opinions that run contrary to those of forest consultants.

In addition, the growing prevalence of uncertainty radically increases the possibility of divergent recommendations concerning proper actions. Strategies to address uncertainty not only influence the outcome (what recommendation is given) but also affect how actors become engaged in an issue and the extent to which they trust professional experts (Peltola, 2013). Addressing uncertainty is therefore critical for forest consultants to demonstrate their trustworthiness, and it constitutes a dynamic condition for their counselling activities. What makes issues involving uncertainty complex and dynamic is that uncertainty is attached to various dimensions, four of which are of particular importance. (i) Cognitive uncertainty concerns inadequate or contingent knowledge regarding the causes and effects of a particular problem, which makes it difficult to suggest relevant interventions. Moreover, in cases in which professional expertise regarding a situation and the proper action to take is definitive, cognitive uncertainty among other actors may hinder these interventions. (ii) The cognitive uncertainty among other actors combined with the fact that other actors may have conflicting interests contributes to strategic uncertainty (van Bueren et al, 2003). This type of uncertainty means that it is difficult to know what action others will take. (iii) Institutional uncertainty (Lidskog et al, 2005) arises when decision making is fragmented, making it difficult to coordinate decisions and actions within a field - that is, to conduct interventions. (iv) Normative uncertainty (cf. Dower, 2007) relates to the absence of shared values and norms or to difficulties in prioritizing among the shared objectives that exist. In most cases, the authority of professional experts is 
partly accorded due to their orientation towards the common good or the public interest, but in cases of normative uncertainty, it is unclear what the common good really is. These four dimensions of uncertainty should not be understood as isolated but in dynamic interaction; one dimension of uncertainty may influence another dimension of uncertainty.

\section{Research Design}

\section{The context: Forest counselling in Sweden}

Forestry is central to the Swedish economy. In 2014, the gross output of the forest sector was SEK 216 billion (equivalent to approximately EUR 22 billion), and the forest and forest industry sector accounted for 11 per cent of the total export value of all goods in Sweden (SFA, 2014, p. 294). The forestry sector currently employs approximately 80000 persons (approximately 2 per cent of the total labour force), a large proportion of whom live in remote areas with few other job opportunities. Thus, forestry-related businesses are very important for the Swedish economy, and there is strong political consensus that forest resources should be used in a way that ensures that they will continue to generate wealth for coming generations. Swedish forest policy is characterized by two main components: (i) the goal of preserving the environment should be given the same importance as the goal of producing woody biomass, and (ii) the governing principle of forest management should be 'freedom with responsibility'; that is, a set of rules should specify the principles for forest use, while the Government acts by providing information, advice and recommendations (Appelstrand, 2012). A third, but less articulated, component is that the aim of forest policy is substantially more farreaching than the official policy goals and legal requirements, that is, a belief and hope that through spreading knowledge and norms, forest owners will do more than what the law requires. A unique feature of Swedish forestry is its ownership structure; approximately 50 per cent of productive forestry land is owned by individuals, 30 per cent is owned by private companies, and 20 per cent is publicly owned (generally by state-owned companies) (SFA, 2014, p. 27). Individually held forestland generally takes the form of small parcels, with approximately 3 per cent (330 000 persons) of the Swedish population owning forestland. Individual forest owners have considerable latitude in how to manage their forests. In a governance system that relies rather heavily on social norms and guidelines to shape individual forest owners' actions, forest consultants play an important role in influencing forest owners' practices.

Some 500 persons are permanently employed as forest consultants at the Swedish Forest Agency (SFA). During 2014, approximately 30000 forest owners participated in individual field activities or group activities organized by the SFA, and 16000 participated in face-to-face counselling activities (SFA, 2015, p. 50). 
In addition to this counselling (which is free of charge), the forest consultants also deliver commercial services, such as courses and plans for felling. In addition, the forest consultants meet with forest owners when conducting supervision (felling and re-plantation are regulated by the Forest Act).

\section{Methods and material}

This article draws on interviews with 19 forest consultants employed by the SFA. In Sweden, the ownership structure varies geographically; in the southern part of the country, non-industrial private forest owners predominate, whereas state-owned or larger privately owned companies or corporations are the norm in the northern part of the country. In addition, there are regional differences in the size and composition of forests. Therefore, consultants were selected from five geographically dispersed regions and from rural and urban areas to transcend local and regional conditions and capture more general circumstances that apply to forest consultancy. Furthermore, the regions selected had different experience of storm damages and, according to current forecasts, differ in terms of the sensitivity of their forests to a changing climate.

A letter was sent to 59 forest consultants, of whom 19 answered in the affirmative, 4 declined to participate in the study and 36 did not respond. Only two interviewees were female, which reflects the general male dominance among forestry consultants. All of them were experienced consultants (on average, they had worked for the SFA for 22 years). All but one had obtained professional education from a university.

The interviews were conducted from October 2014 to January 2015. The interviews were semi-structured and used an interview guide that allowed the interviewers to ask follow-up questions and expand on themes that emerged during the interview. The interviews were tape recorded and transcribed verbatim. A contextualized thematic analysis was conducted (Bryman, 2012) using NVivo software to analyse the qualitative data. During the analysis, particular attention was paid to thematising everything that was said concerning risk, uncertainty, knowledge, advice and the consultants' general working conditions. In so doing, we reconstructed how the forestry consultants address uncertainties and transform them into manageable risks. In the analysis, we use the notion of strategies to capture the different ways in which the consultants cope with uncertainties. Because of the relatively limited number of forest consultants employed by the SFA, we do not provide information on the regions in which they work to avoid identifying them (see the appendix for additional information on the respondents).

\section{Challenges: Resource Constraints and Uncertainties}

Despite no explicit question having been asked about it, constant cutbacks emerged as a recurrent theme in all interviews. Organizational downsizing and 
budget reductions may be compensated for by developing other organizational routines and ways to perform counselling. However, uncertainty may arise if resources are constantly reduced or during periods of rapid changes to organizational routines and work practices. In particular, the forest consultants stressed: (i) increased administrative burden (due to administrative downsizing), (ii) less time for in-field counselling, (iii) difficulties in meeting the demand for counselling, (iv) fewer possibilities to follow-up on suggested interventions, (v) less time to keep up with new research and directives, (vi) poorer tools for environmental protection, for example, reduced economic resources for purchasing land for conservation purposes, and (vii) restricted opportunities to counsel on production issues, such as cleaning and thinning. Thus, the persistent reductions in the amount of time available for counselling results in an uncertainty over how to effectively perform it, including how to consider and address the four dimensions of uncertainty discussed below. In addition, the struggle to maintain and achieve epistemic authority does not take place in a material vacuum (Spinardi, 2014); resources are important conditions for developing and implementing strategies.

\section{Cognitive uncertainty}

Nearly all accounts of cognitive uncertainty provided in the interviews relate to climate change. Even when discussing general questions regarding knowledge gaps, uncertainties involving climate change were frequently articulated. In addition to climate change, some of the interviewees expressed uncertainty regarding the long-term effects of clear-cutting on biodiversity and the possible depletion of soils due to intensive forestry.

The forest consultants expressed certainty that climate change is taking place, and they supported their certainty by referring to a multitude of sources, such as general opinion, research, own personal experiences and the general policy of the SFA. Thus, climate change is an important condition to consider in their counselling activities. They simultaneously acknowledged considerable uncertainties concerning the effects of climate change and how to address them, not least: (i) the pace and magnitude of change; (ii) optimal tree species given the changed climate; (iii) new or dramatic increases in destructive pest agents; (iv) new conditions for clear-cutting (not least that wet soil will likely make it more difficult to use heavy forest machinery); and (v) recurring storms causing large wind-throws. A particular dilemma is that, because the forest cycle in Sweden typically extends approximately 80 years into the future, decisions taken in the present must consider future circumstances while simultaneously being compatible with present conditions (for example, trees suited for a warmer climate might not grow well today).

Many of the consultants are convinced that particular actions should be taken in the face of climate change, such as blending in more deciduous species 
(for example, birch). However, they find that the cognitive uncertainties among other actors (not least forest owners) may hinder such interventions. Cognitive uncertainties thus constitute a challenge to the consultants' epistemic authority because inadequate or contingent knowledge makes it difficult to suggest interventions.

\section{Strategic uncertainty}

A degree of strategic uncertainty follows from the governing principle 'freedom with responsibility'. A de-regulated system makes it more difficult to know what action others will take. However, the forest consultants seem accustomed to this situation and they stressed that the final decision rests with the forest owner. Their general view is that forest owners generally heed their advice, and in those cases in which they ignore them, it does not constitute a threat to the consultants' epistemic authority (that is, forest owners may generally trust the consultants' competence, even if they do not follow every suggestion).

A major reason for strategic uncertainty is the increasingly heterogeneous composition of contemporary forest owners. Forest entities differ in size and composition, and forest owners have different levels of competence in forestry. Contemporary processes of individualization and urbanization have further complicated this heterogeneous situation. Individualization entails the dismantling of status-derived authority. Historically, the local forester was an important person in the community. Some of the older consultants spoke of a time when forest owners almost stood at attention when they met them. They mentioned that some older forest owners that continue to occasionally ascribe status-derived authority to them, whereas younger owners adopt a more critical stance towards this type of authority. On the other hand, the older generation may be more familiar with practical forestry and somewhat reluctant to adopt new methods. One respondent summarized the differences as follows:

IP14: [The younger generation] take a more critical stance and ask a lot more questions, which is probably natural because, for one thing, it's a generational question, but they also might lack basic knowledge, while the older category of forest owners can be a bit troublesome because they're often stuck in the old forestry policy and are a bit hard to influence in that way, yet still they're not quite as critical. So you have to put it on completely different levels.

Urbanization has implied that an increased number of forest owners live remote from their property. For geographical reasons it might be more difficult to advise such owners, but the remote owners may also develop different attitudes towards forestry. If they have inherited the forest as part of a family farm - while having chosen a different and urban life for themselves - they might be less committed to managing their forest. Or, if they mainly visit the 
property on vacations and such, they might be reluctant to adopt interventions that change how the forest looks. There are also examples of urban elites buying large properties as a life-style investment, without any prior knowledge in forestry. Of course, these types of forest owners coexist with old types. As the composition of forest owners gets more heterogeneous, the strategic uncertainty increases. This means that counselling becomes more complex, as different categories of forest owners are in need of different advice and will also adopt it differently.

\section{Institutional uncertainty}

Swedish forest owners have considerable freedom in managing their forests. Theoretically, this would imply a relatively uncomplicated counselling task for the consultants: aid the forest owners in their work to meet the (few) legal requirements and in their general management of their forests. In practice, however, there are institutional factors complicating this task. As discussed above, many contemporary forest owners lack theoretical and/or practical knowledge in forestry, making them more reliant on external advice. The SFA is far from capable of satisfying all of the demand for in-field counselling, whereas forest companies are eager to provide in-field counselling - which facilitates their purchasing the wood. It is more the rule than the exception that forest owners allow forest companies to manage the operation in question, including marking up the area and reporting the felling to the SFA. This is typically when the forest consultants begin to play a role, as a felling report may alert them that specific considerations should be made at the site. Several consultants interviewed would prefer to enter the process at an earlier stage, when they would have better opportunities to influence the forest practices of the forest owners:

IP15: So it could definitely be worthwhile if people, as you said, before they talk with the representative, if they'd maybe talked with us, to get another viewpoint on things, maybe a bit more objective.

The consultants portray the buyers as professional and honest; the difference is that buyers have a strictly commercial perspective. In addition, forest companies often outsource their production resources, using contractors for the various operational tasks. This means that decisions are taken on at least three different levels. One of the consultants summarizes the problem of fragmented decision making:

IP12: It can be a bit difficult sometimes, because even the forest owners are often several steps removed when, when a felling is being planned, that I might give advice to the owner, and then he talks to a sawmill that will fell the trees, and the sawmill has a subcontractor, and the subcontractor has a subcontractor to clear 
undergrowth, and it's easy for something to get lost in all those steps. So it doesn't always turn out like either we or the owner had planned.

Institutional uncertainty also stems from organizational considerations within the SFA. The resource constraints the agency has faced have resulted in a reduced presence of consultants in the forest sector, making it more difficult to influence and coordinate decisions taken within it:

IP16: There used to be ten districts in this county [now there is one, our remark]. Now the basis for cultivating, so to speak, a more tight, close relationship with the forestry, it's significantly worse.

These various forms of institutional uncertainty are indirect threats to authority. Fragmented decision making makes it more difficult to conduct or suggest interventions, that is, to fulfil the professional claim. Fragmentation makes it more difficult for the forest consultants to identify feasible strategies to influence forest practices.

\section{Normative uncertainty}

Swedish forest policy accords equal priority to preserve the environment and to produce woody biomass. At the micro level of everyday forestry, this policy implies an institutionalization of normative uncertainty. Forest consultants and industry buyers often have different views of how this balance should be struck at the individual site. A majority of the consultants interviewed find themselves competing with the buyers to secure the forest owners' attention; the consultants constantly stress environmental values, while the buyers primarily emphasize production value. The owners differ substantially in their attitudes towards the environment and production, and hence how 'rough' the competition becomes varies. In addition, individual forest consultants differ in how they value nature and production. This means that there are elements of internal normative uncertainty at play:

IP11: Not to name names, but there are a number of people who might seem, they're very interested in conservation issues but don't know a thing about forestry in practice, and they might give the forest owners advice that, it's impossible to carry out with today's machines, you'd have to go around with an axe or something ... I think, I think they're on the wrong track, I really think so.

Other examples of normative uncertainty include how recreational/social values should be weighed against production values or how nature values should be weighed against cultural values (for example, old sallow of conservation value may grow amidst ancient remains that have cultural value). Even if 
the forest consultants have legal authority over certain issues, they unanimously prefer to use counselling tools rather than issuing prohibition notices. The reason for this is that they consider counselling effective, although the primary reason is to avoid role conflicts; it is difficult to combine the role of the 'law enforcer' with the trust-based relationship between consultant and client.

Hence, normative uncertainty challenges epistemic authority in at least three ways. First, if it is unclear what the common good or public interest actually is, then the authority that typically flows from the professional expert's orientation towards such values is no longer effective. Instead, authority in such a context requires that strong arguments can be made in favour of a value. Second, internal normative uncertainty undermines authority derived from belonging to a united profession because the presence of different value orientations within the profession makes it possible to question the consultants' claims with reference to their own peers. Third, a permanent presence of values that are often difficult to reconcile may erode the general trust in the ability of professional expertise to provide normative guidance.

\section{Strategies for Addressing Uncertainty}

In our analysis, we find that the forest consultants employ seven main strategies to address different types of uncertainty.

\section{Disclosure and risk diversification}

A central strategy for addressing the cognitive uncertainties surrounding climate change is to disclose them to the forest owners. This is achieved by referring to research with different conclusions and providing the forest owners with different scenarios. The consultants often state what they (and the SFA) feel is the most likely scenario. Referring to (divided) research on climate change externalizes the knowledge uncertainties from the forest consultant profession, and by presenting different possible scenarios, the consultants appear knowledgeable. Rather than providing certainty, the consultants assume the role of professional navigators in a landscape populated by risks and uncertainties. Because the uncertainties of climate change are well known to the general public, it is unlikely that the consultants would appear trustworthy if they did not acknowledge them. Following from this approach to framing the issue of climate uncertainty, the consultants strongly argue for a strategy of risk diversification, such as planting different tree species and applying varying forestry methods on one's property. Some consultants also stress how a wellkept forest - according to standard forestry practice - becomes more resilient to extreme events such as storms and heavy precipitation. Here, the prevalence of uncertainty is used as argument for active management. Uncertainty, then, is 
not only a hindrance to action, but it can also be used strategically to motivate action.

\section{Using historical references}

When asked how they arrive at various interventions, the consultants often refer to their theoretical and practical knowledge. However, the cognitive uncertainties related to climate change and the strategic uncertainties related to a more critical breed of forest owners mean that knowledge claims must be supported by some type of evidence. In this regard, the consultants highlight the importance of using historical references in their in-field counselling: visible examples of the outcomes of various mechanisms in the forest. The basic idea is that past and present circumstances provide information that can be extrapolated into the future, resulting in a form of localized evidence-based practice. Forest owners often have stands (that is, groups of trees) on their property that differ in age, dominant species, interventions made, and so on, and comparing the conditions of different stands to one another provides evidence of what is effective. Thus, whereas climate change often is framed as a challenge that renders historical knowledge less relevant, here, historical references are used to motivate and guide interventions. By using historical references, the practical knowledge of how forests work becomes relevant even when facing abstract risks such as predicted climate change.

\section{Contextualized and strategic counselling}

Providing advice is an interpretative activity; to be effective, the advice-giver must consider how particular advice will be understood by the target group. As described above, forest owners are heterogeneous group, which forest consultants must consider when developing advice. By gathering information on individual forest owners and their intentions concerning their forests, it becomes possible to develop relevant and feasible advice. The forest consultants also stress that being a good listener is important for building trust. In the interviews, they provided numerous examples of this type of contextualized counselling, including: (i) not suggesting interventions that are unlikely to be executed by the forest owner in question, (ii) alluding to historical continuity when arguing for more active management to an owner who recently inherited her forest and (iii) avoiding complex theoretical elaborations when interacting with inexperienced owners. Even if contextualization can be partly achieved by using modern communication tools, the consultants believe that it is nearly impossible to develop familiarity with a forest without a physical visit, as every stand possesses unique features. In addition, the consultants stressed that face-to-face interactions are the most effective means for building trustful relationships. 
With less time for in-field counselling, it is less feasible to pursue the strategy of contextualizing advice. The SFA has had several counselling programs targeting specific issues in recent years, such as climate change, forestry and water systems, procurement skills, and so on. Even if the consultants value such temporary additional resources for in-field counselling, they also lament that targeted programs offer less room for general discussions with forest owners. This brings us to the related strategy of using strategic counselling. By this, we mean that the forms of and circumstances for counselling are geared towards achieving the best effect, and targeted programs would be an example of this at the central level. The individual consultants also apply strategic measures in their own practices, such as encouraging owners, buyers and contractors to jointly attend in-field counselling. This is effective in countering institutional uncertainty, as 'group counselling' facilitates negotiating and coordinating actions. It also counters normative uncertainty, as group dynamics may be effective in securing norm-following behaviour. In line with this, providing infield feedback to buyers (a form of strategic counselling) may have a discouraging effect on future transgressions:

IP08: [W] actually go out with the representatives and ... They really do have to account for themselves, "what the heck were you thinking? There used to be a little stream here, now you've destroyed everything, by all means please explain yourselves". Maybe then it will be harder for them the next time they want to plan a felling.

\section{Negotiating values and decoupling practices}

As stated above, in line with the Swedish forest model, the consultants aim higher than the standard set by law. Therefore, a satisfactory end result from the consultant's perspective typically requires negotiation or bargaining. Empirical accounts include: (i) asking a forest owner to save a stand of particular conservational value, and suggesting greater felling in another area as compensation, (ii) informing the forest owner of rare plants or birds inhabiting the area, thereby getting her to reevaluate her forest and (iii) arguing for recreational values that if preserved would also benefit environmental aspects. The consultants believe that such negotiations are effective, at least in convincing the forest owner and thus in maintaining authority. At a later stage, a buyer might be equally successful in her negotiations with the owner, which means that the end result might differ.

Resource constraints, however, may result reduced ambitions. For instance, consultants regret they have little opportunity for counselling on production issues. This also has implications for their epistemic authority because, in line with their professional claim, the consultants are considered knowledgeable in all areas regarding forestry. The consultants attempt to provide answers to any 
forest-related questions regardless of resource constraints. This is a mild but common form of decoupling, that is, resisting change by doing something other than what is formally prescribed within an organization (Meyer and Rowan, 1977). Decoupling might be a necessary strategy to uphold epistemic authority in the face of resource constraints. Other examples of this strategy include highly selective readings of internal information circulated and the continuation of established local practices despite central directives. Hence, decoupling can be used to address institutional uncertainty.

\section{Conclusion}

Forest consultants face a number of different uncertainties in their professional practice and have developed a number of strategies to address them. In so doing, they strive to gain, or at least maintain, epistemic authority without compromising their professional claim. The results of this study support those of earlier studies reporting that trust in authorities is something that is actively achieved (Giddens, 1991; Reed, 1996; Pfadenhauer, 2006; Navin, 2013). The interviewed forest consultants unanimously stressed the importance of actively building trust by being context-sensitive and receptive to the forest owners' experience and interest. The contribution of this study is its stress on the multidimensionality of uncertainty. This approach makes it possible to separate different challenges that uncertainties may create and various strategies to address them. In particular, we will stress four implications of this finding.

First, a multidimensional conceptualization of uncertainty makes it possible to understand that the cognitive uncertainty in the case considered in this study is a minor problem, despite that numerous public and scientific debates focus on this type of uncertainty. The forest consultants stated that their profession is not accountable for this type of uncertainty; it arrives from the scientific community. By locating the uncertainty outside their profession, they can retain epistemic authority while simultaneously articulating numerous cognitive uncertainties. In this case, the forest consultants can be regarded as professional navigators in a landscape populated by risks and uncertainties. By spreading risk consciousness and providing a map of a risky terrain with no clear tracks, they create the possibility for discussion and negotiation with the forest owners concerning the optimal path. Thus, the advice the consultants provide indicates which risks to avoid. One reason for this is, as Beck has stressed, that risk consciousness indicates what to avoid but never what to seek (Slater and Ritzer, 2001; Beck, 2009).

Second, the study explains why other forms of uncertainty - strategic, institutional and normative - are more difficult to address. Because they cannot be easily located outside of the profession, these forms of uncertainty more directly interfere with the consultant's ability to perform in keeping with her professional claim. For example, the professional claim involves: (i) knowing 
how others are likely to act, (ii) being able to coordinate decision making and (iii) knowing how to balance between different policy goals (in this case, between the forest policy goals of production and environment). Thus, stressing strategic, institutional and normative uncertainties means that what is needed to enable the consultants to provide advice is not primarily a question of gathering additional (scientific-technical) knowledge.

Third, uncertainty is often framed in the scientific and public debate as constituting a hindrance to action. However, uncertainties can also be used to facilitate action. As our analysis has shown, uncertainty may not question the epistemic authority of the forest consultants but can instead be used as an opportunity for interaction, discussion and negotiation. Uncertainty can be used as a 'boundary-ordering device' (Shackley and Wynne, 1996; Gieryn, 1999) that, in certain circumstances, serves as a means to reconcile different interests (or to deepen the conflict between them).

Fourth, when confronting uncertainty, it is also important to stress the differentiated role of resource constraints. Epistemic authority is often negotiated and achieved in interaction with clients. As other studies have shown, this interaction is often diverse, context-sensitive and dynamic (Corvellec, 2009; Mahony, 2013). Epistemic authority is largely negotiated at the local level, in concrete meetings between professionals and clients. As we find in our analysis, with increasingly less time for in-field visits it may be difficult for the forest consultants to maintain their epistemic authority on and influence over forest owners' practices in the long run. Under a de-regulated system - such as the Swedish forest governance system - the importance of boundary spaces increase; these are performative spaces where epistemic and normative authority are negotiated and developed. Because of resource constraints, there is a risk that the direct interaction with experts will be hollowed out, and virtual spaces (for example digitalized services offered through Websites) may not successfully develop relevant and applicable advice for all types of forest owners.

To conclude, uncertainty implies a multifarious challenge for the epistemic authority of professional expertise. However, as this article has shown, these challenges do not necessarily constitute a hindrance to professional experts' strive to support their professional claim but can instead be addressed and even actively exploited in the effort to provide advice and maintain and achieve authority.

\section{Acknowledgements}

This article was written as part of the Swedish interdisciplinary programme Future Forest financed by Mistra (The Foundation for Strategic Environmental Research); Forestry Research Institute of Sweden (Skogforsk); Swedish University of Agricultural Sciences (SLU); and Umeå University. 


\section{References}

Abbott, A. (1988) The System of Professions: An Essay on the Division of Expert Labor. Chicago, IL: University of Chicago Press.

Appelstrand, M. (2012) Developments in Swedish forest policy and administration: From a 'policy of restriction' towards a 'policy of cooperation'. Scandinavian Journal of Forest Research 27(2): 186-199.

Barry, A., Osborne, T. and Rose, N. (eds.) (1996) Foucault and Political Reason: Liberalism, Neo-Liberalism, and Rationalities of Government. Chicago, IL: University of Chicago Press.

Beck, U. (2009) World at Risk. Cambridge, UK: Polity.

Beck, U. and Beck-Gernsheim, E. (2004) Families in a runaway world. In: J. Scott, J. Treas and M. Richards (eds.) The Blackwell Companion to the Sociology of Families. Malden, MA: Blackwell, pp. 499-514.

Boholm, A. (2010) On the organizational practice of expert-based risk management: A case of railway planning. Risk Management 12(4): 235-255.

Brante, T. (2011) Professions as science-based occupations. Professions and Professionalism 1(1): 4-20.

Bryman, A. (2012) Social Research Methods. 4th edn. Oxford: Oxford University Press.

Callon, M., Barthe, Y. and Lascoumes, P. (2009) Acting in an Uncertain World. Cambridge, MA: MIT Press.

Collins, H.M. and Evans, R. (2007) Rethinking Expertise. Chicago, IL: University of Chicago Press.

Corvellec, H. (2009) The practice of risk management: Silence is not absence. Risk Management 11(3-4): 285-304.

Dower, N. (2007) World Ethics. The New Agenda. 2nd edn. Edinburgh, UK: Edinburgh University Press.

Eyal, G. (2013) For a sociology of expertise: The social origins of the autism epidemic. American Journal of Sociology 118(4): 863-907.

Giddens, A. (1990) The Consequences of Modernity. Stanford, CA: Stanford University Press.

Giddens, A. (1991) Modernity and Self-Identity: Self and Society in the Late Modern Age. Cambridge, UK: Polity press.

Gieryn, T.F. (1999) Cultural Boundaries of Science: Credibility on the Line. Chicago, IL: University of Chicago Press.

Haas, P.M. and Stevens, C. (2011) Organized science, usable knowledge, and multilateral environmental governance. In: R. Lidskog and G. Sundqvist (eds.) Governing the Air. The Dynamics of Science, Policy, and Citizen Interaction. Cambridge, MA: MIT Press, pp. 125-162.

Hughes, E.C. (1963) Professions. Daedalus 92: 655-668.

Hughes, E.C. (1981) Men and their Work. Westport, CO: Greenwood Press, [original 1958].

Irwin, A. and Michael, M. (2003) Science, Social Theory and Public Knowledge. Maidenhead, UK: Open University Press.

Lidskog, R. (2008) Scientised citizens and democratised science. Re-assessing the expertlay divide. Journal of Risk Research 11(1-2): 69-86.

Lidskog, R. and Sjödin, D. (2015) Risk governance through professional expertise. Forestry consultants' handling of uncertainties after a storm disaster. Journal of Risk Research 18, doi: 10.1080/13669877.2015.1043570. 
Lidskog, R., Soneryd, L. and Uggla, Y. (2005) Knowledge, power and control. Studying environmental regulation in late modernity. Journal of Environmental Policy \& Planning 7(2): 89-106.

Lidskog, R. and Sundqvist, G. (2013) The sociology of risk. In: S. Roeser, R. Hillerbrand, P. Sandin and M. Peterson (eds.) Essentials of Risk Theory. New York: Springer, pp. $75-105$.

Lofstedt, R.E. (2005) Risk Management in Post Trust Societies. Basingstoke,UK and Hampshire, UK: Palgrave Macmillan.

Mahony, M. (2013) Boundary spaces: Science, politics and the epistemic geographies of climate change in Copenhagen, 2009. Geoforum 49: 29-39.

Meyer, J.W. and Rowan, B. (1977) Institutionalized organizations: Formal structure as myth and ceremony. American Journal of Sociology 83(2): 340-363.

Miller, C.A. (2001) Hybrid management: Boundary organizations, science policy, and environmental governance in the climate regime. Science, Technology, \& Human Values 26(4): 478-500.

Navin, M. (2013) Competing epistemic spaces: How social epistemology helps explain and evaluate vaccine denialism. Social Theory and Practice 39(2): 241-264.

Nowotny, H., Scott, P. and Gibbons, M. (2001) Re-Thinking Science. Knowledge and the Public in an Age of Uncertainty. Cambridge, UK: Polity Press.

Palmer, J. (2012) Risk governance in an age of wicked problems: Lessons from the European approach to indirect land-use change. Journal of Risk Research 15(5): 495-513.

Peltola, T. (2013) Responsible action as embedded in knowledge practices: An analysis of forest biodiversity protection. Science, Technology \& Society 18(1): 29-50.

Pfadenhauer, M. (2006) Crisis or decline? Problems of legitimation and loss of trust in modern professionalism. Current Sociology 54(4): 565-578.

Raviv, A., Bar-Tal, D., Raviv, A. and Abin, R. (1993) Measuring epistemic authority: Studies of politicians and professors. European Journal of Personality 7(2): 119-138.

Reed, M.I. (1996) Expert power and control in late modernity: An empirical review and theoretical synthesis. Organization Studies 17(4): 573-597.

Schön, D.A. and Rein, M. (1994) Frame Reflection. Toward the Resolution of Intractable Policy Controversies. New York: Basic Books.

SFA (2014) Swedish Statistical Yearbook of Forestry. Jönköping, Sweden: Swedish Forest Agency.

SFA (2015) Annual Report 2014. Jönköping: Swedish Forest Agency.

Shackley, S. and Wynne, B. (1996) Representing uncertainty in global climate change science and policy: Boundary-ordering device and authority. Science, Technology, \& Human Values 21(3): 275-302.

Slater, D. and Ritzer, G. (2001) Interview with Ulrich Beck. Journal of Consumer Culture 1(2): 261-277.

Smith, D. and Fischbacher, M. (2009) The changing nature of risk and risk management: The challenge of borders, uncertainty and resilience. Risk Management 1(11): 1-12.

Spinardi, G. (2014) Technical controversy and ballistic missile defence: Disputing epistemic authority in the development of hit-to-kill technology. Science as Culture 23(1): 1-26.

Van Asselt, M.B. and Renn, O. (2011) Risk governance. Journal of Risk Research 14(4): 431-449.

van Bueren, E., Klijn, E.-H. and Koppenjan, J.F.M. (2003) Dealing with wicked problems in networks: Analyzing an environmental debate from a network perspective. Journal of Public Administration Research and Theory 13(2): 193-212.

Webster, A. (2002) Innovative health technologies and the social: Redefining health, medicine and the body. Current Sociology 50(3): 443-457. 


\section{Appendix}

\section{List of interviewees}

Given the small number of publicly employed forest consultants in Sweden and the fundamental importance of protecting respondent confidentiality, we do not provide information about specific regions that were included.

[Respondent number. Position(s). Education. Years at the SFA. Interview date]

1. Forest consultant. Bachelor of Science in Forest Management. 30. 14-10-07

2. Forest consultant. No formal. 10. 14-10-13

3. Forest consultant. Master of Science in Forestry. 2. 14-10-16

4. Forest consultant/District manager. Bachelor of Science in Forest Management. 20. 14-10-21

5. Forest consultant specializing in cultural heritage. Master of Science in Archaeology. 7. 14-10-22

6. Forest consultant. Master of Science in Forestry. 38. 14-11-04

7. Forest consultant. Higher Education Degree in Forest Management. 13. 14-11-04

8. Forest consultant. Bachelor of Science in Forest Management. 13. 14-11-04

9. Forest consultant. Higher Education Degree in Forest Management. 31. 14-11-05

10. Forest consultant. Higher Education Degree in Forest Management. 34. 14-11-07

11. Forest consultant. Higher Education Degree in Forest Management. 35. 14-11-12

12. Forest consultant. Bachelor of Science in Forest Management. 31. 14-11-12

13. Forest consultant. Higher Education Degree in Forest Management. 26. 14-11-14

14. Forest consultant. Higher Education Degree in Forest Management. 32. $14-11-14$

15. Forest consultant. Bachelor of Science in Forest Management. 3. 14-11-17

16. Forest consultant. Master of Science in Forestry. 33. 14-11-17

17. Forest consultant. Higher Education Degree in Forest Management. 1. 14-12-04

18. Forest consultant. Master of Science in Forestry. 30. 14-12-04

19. Forest consultant/Coordinator knowledge dissemination. Master of Science in Forestry. 33. 14-12-01

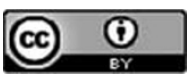

This work is licensed under a Creative Commons Attribution 3.0

Unported License. The images or other third party material in this article are included in the article's Creative Commons license, unless indicated otherwise in the credit line; if the material is not included under the Creative Commons license, users will need to obtain permission from the license holder to reproduce the material. To view a copy of this license, visit http:// creativecommons.org/licenses/by/3.0/ 